\title{
Eine Rechtsbuch-Handschrift aus Bremervörde
}

\author{
Ralf G. Päsler
}

$\mathrm{D}$ ie Handschriftendichte im Norden, speziell im Dreieck der Weser- und Elbemündungen, ist recht gering. Umso erfreulicher ist der Hinweis auf einen spätmittelalterlichen Codex, der - wie es scheint - auf eine bereits ältere Texttradition zurückgeht. Es handelt sich um das Bremervörder Stadtrechtsbuch in Bremervörde, Kreisarchiv des Landkreises Rotenburg (Wümme), Best. CI Stadt Bremervörde, Nr. I (Kurzform: Kreisarchiv ROW, CI Nr. I).

Erfreulich ist der Hinweis auch, weil der Codex dem ,Handschriftencensus' bislang unbekannt ist. Dies ist insofern ungewöhnlich, da von der Handschrift seit 2009 ein Faksimile existiert. ${ }^{I}$ Dieser Umstand wird aber verständlich, weil die wissenschaftliche Fachliteratur die Handschrift nicht erwähnt, auch nicht die Berichte Conrad Borchlings von seiner Handschriftensuche, die ihn nur nach Stade oder Zeven, also an Bremervörde vorbeigeführt hatte. ${ }^{2}$

Das erwähnte Faksimile stellt Handschrift und Text knapp vor, bietet Abbildungen der beschriebenen Seiten und neben einer Übersetzung auch eine Transkription mit Vergleich verwandter Texte (s.u.).

Die Entstehungszeit wird mit Anfang des I5. Jahrhunderts (S. 9) angegeben, wenngleich die Datierung solch elaborierter gotischer Buchschriften schwierig ist (Abb. I). ${ }^{3}$ Der Buchblock ist $29,5 \times 20 \mathrm{~cm}$ groß und umfasst 6I Blätter. Größe des Schriftspiegels ist 20,5-2I,2 × I2,6-I4 cm; die Blätter sind liniert für 22 Zeilen. ${ }^{4}$ Der Buchdeckel besteht aus Holz mit braunem Lederüberzug mit umfangreicher Streicheisen- und Einzelstempelverzierung (Ende 15. oder Anfang I6. Jahrhundert).

Der Inhalt verteilt sich wie folgt: Bl. Ir ist leer; auf Bl. Iv finden sich drei jüngere Einträge, die Besitzverhältnisse in und um Bremervörde festhalten. ${ }^{5}$ Das eigentliche Rechtsbuch nimmt die Blätter 2r bis 49v ein. Nach einer Leerseite ( $5 \circ r)$ folgen bis Bl. $55 \mathrm{v}$ Nachträge bzw. Ergänzungen zu einzelnen Kapiteln. Direkt anschließend sind bis $\mathrm{Bl}$. $57 \mathrm{r}$ vier Urkunden von jüngeren Händen des I6. Jahrhunderts eingetragen. ${ }^{6}$ Von B1. $57 \mathrm{v}$ bis $6 \mathrm{Ir}$ folgen wiederum Leerseiten; auf Bl. 6IV findet sich auf Zeile fünf eine Überschrift, Menschen Kindeß Hand (17. Jahrhundert).

Nach Ausweis der Edition handelt es sich um die Abschrift einer älteren Vorlage, die in Zusammenhang mit der Erhebung Bremervördes (zeitgenössisch Vörde) zur Stadt Anfang des I4. Jahrhunderts entstanden sein soll. Es könnte sich bei dem Bremervörder Codex somit um eine Ersatzhandschrift für die im Laufe der Zeit zerschlissene Originalhandschrift handeln. Der Text steht dem Buxtehuder Stadtrecht nahe, das seinerseits ein Ableger des Stader Stadtrechts ist, das wiederum mit dem Hamburger Ordeelbook von I270 verwandt ist. Die Bremervörder Handschrift ist somit ein weiteres Puzzleteil in der Hamburger Stadtrechtsfamilie.

\section{Kontakt}

Ralf G. Päsler

Philipps-Universität Marburg · Institut für Deutsche Philologie des Mittelalters · Deutschhausstr. I5 35037 Marburg E-Mail: paesler@staff.uni-marburg.de 


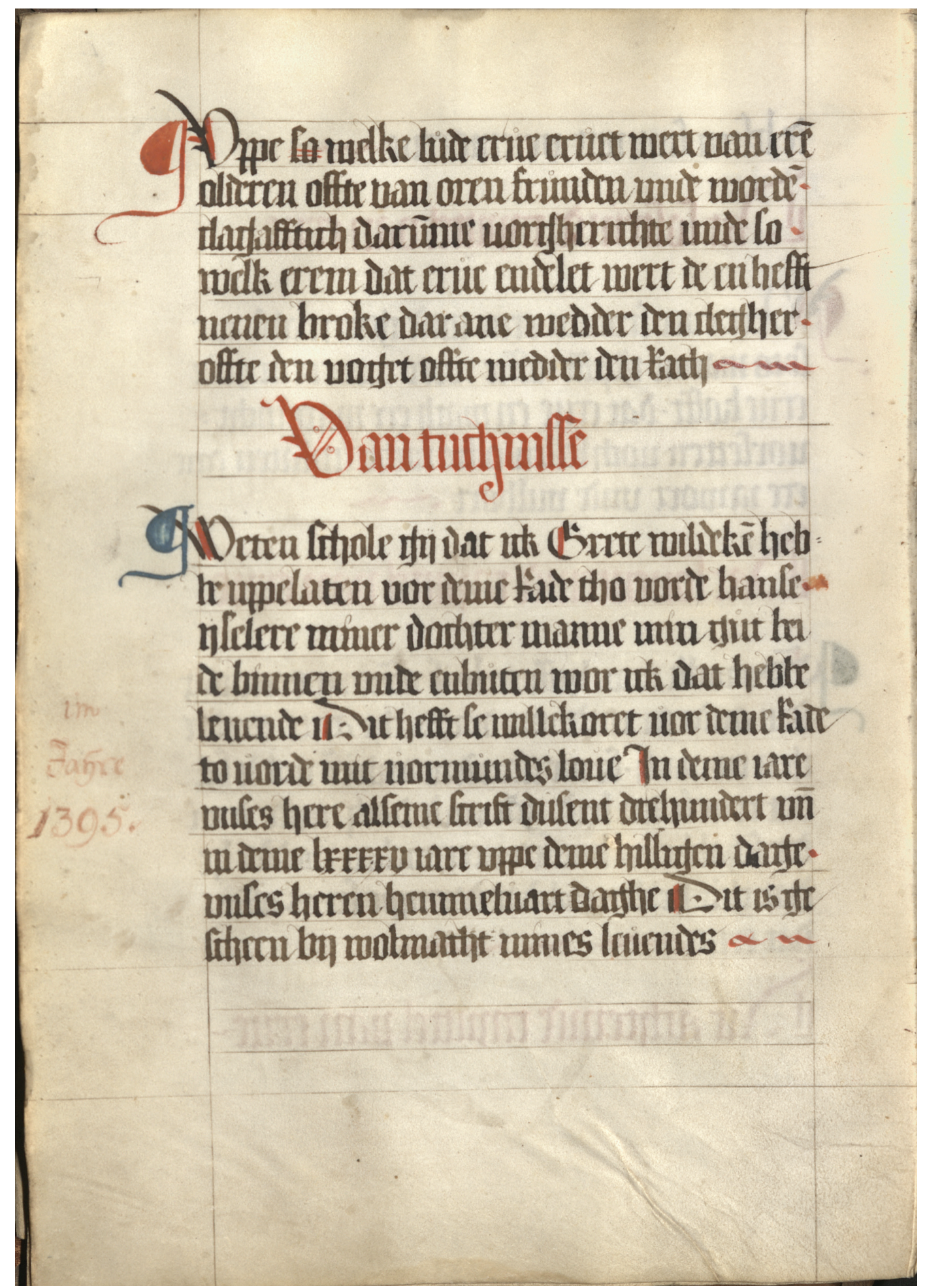

Abb. I: Bremervörder Stadtrechtscodex, Bl. 7v 


\section{Anmerkungen}

I Reinhard Scheelje (Bearb.), Der mittelalterliche Bremervörder Stadtrechtskodex (Schriftenreihe des Landschaftsverbandes der ehemaligen Herzogtümer Bremen und Verden 34), Stade 2009.

2 Conrad Borchling, Mittelniederdeutsche Handschriften in Norddeutschland und den Niederlanden. Erster bis vierter Reisebericht, in: Nachrichten von der Königl. Gesellschaft der Wissenschaften zu Göttingen, Philol.-hist. Klasse, Göttingen I898-ı113 [Heft 2 (I898), Beiheft (1900), Beiheft (1902), Beiheft (1913)].

3 Vornehmlich wird die Datierung aus einer Beischrift zu einer bei der Abschrift in den Text übernommenen Urkunde (Bl. 7v, Faksimile [Anm. I], S. 32) abgeleitet; diese Urkunde wird am Rand auf I395 datiert.

4 Für Informationen danke ich Sönke Kosicki vom Kreisarchiv Bremervörde herzlichst.

5 Vgl. Scheelje [Anm. I], S. 20.

6 Die Datierungen der Urkunden sind: zweimal 29. Dez. 1528, sowie 6. Jan. 568 und 26. Aug. I576; Ausstellungsort ist jeweils Bremervörde. 